\title{
Budesonide $\mathrm{MMX}^{\mathrm{TM}}$ Is Effective in Patients Having Persistent Symptoms and Raised Fecal Calprotectin Following Treatments for Diverticular Disease
}

\author{
Antonio Tursi ${ }^{1}$, Claudio Cassieri ${ }^{2}$, Raffaele Colucci ${ }^{3}$, Walter Elisei ${ }^{4}$, Marcello Picchio ${ }^{5}$, Giovanni Brandimarte ${ }^{2}$
}

1) Territorial Gastroenterology Service, ASL BAT, Andria, Italy;

2) Division of

Internal Medicine and Gastroenterology, "Cristo Re" Hospital, Rome, Italy;

3) Digestive Endoscopy Unit, "San Matteo degli Infermi" Hospital, Spoleto (PG), Italy; 4) Division of

Gastroenterology, ASL Roma 6, Albano Laziale (Roma), Italy;

5) Division of Surgery, "P. Colombo" Hospital, ASL Roma 6, Velletri (Rome), Italy

Address for correspondence: Antonio Tursi, MD Servizio di Gastroenterologia Territoriale

DSS n ${ }^{\circ} 4$, ASL BAT

Via Torino, 49

76123 Andria (BT), Italy

antotursi@tiscali.it

\section{ABSTRACT}

Background \& Aim: Although rifaximin and mesalazine seem to be effective in treating the majority of people suffering from diverticular disease (DD), some patients still experience symptoms following those treatments. The aim of this study was to assess the efficacy of budesonide $\mathrm{MMX}^{\mathrm{TM}}$ in managing symptoms and raised fecal calprotectin (FC) in patients with endoscopic diagnosis of DD and not responding to standard treatments. Methods: We performed a post-hoc analysis of the patients enrolled in the DICA prospective study. All patients were at the first diagnosis of DD, scored according to DICA classification. We assessed abdominal pain, meteorism, constipation and diarrhea (scored from 0 to 10) and FC expression at baseline and after six months. Patients were treated with budesonide $\mathrm{MMX}^{\mathrm{TM}}$ for 4 weeks $(9 \mathrm{mg} /$ day for 2 weeks, followed by $9 \mathrm{mg}$ every other day for further 2 weeks), followed by mesalazine 2.4 grams/day for further 5 months.

Results: We studied 24 patients (18 females and 6 males, median age 64, inter quartile range (IQR): 57.573.5), previously treated with mesalazine and/or rifaximin (equally subdivided between DICA 2 and DICA 3). At 6-month follow-up, a significant reduction of all symptoms assessed was observed (abdominal pain and meteorism: $\mathrm{p}<0.001$; constipation: $\mathrm{p}=0.007$; diarrhea: $\mathrm{p}=0.009$ ). Median (IQR) FC level was 244.5 (171.5322.0) $\mu \mathrm{g} / \mathrm{g}$ at baseline and 51.0 (IQR: 35.5-61.5) $\mu \mathrm{g} / \mathrm{g}(\mathrm{p}<0.001)$ after 6 months. No side effects were recorded. Conclusions: Treatment with budesonide $\mathrm{MMX}^{\mathrm{TM}}$ seems to be effective in obtaining symptoms' control and dropping of FC in patients with DD and not responding to standard treatments.

Key words: acute uncomplicated diverticulitis - budesonide - fecal calprotectin.

Abbreviations: DICA: Diverticular Inflammation and Complication Assessment; DD: diverticular disease; FC: fecal calprotectin; MMX: multi-matrix system; SCAD: segmental colitis associated with diverticulosis.

\section{INTRODUCTION}

Diverticular disease (DD) is commonly found in developed countries, slightly more frequently in the USA than in Europe. It was considered a rare condition in Africa and developing countries, but new data showed an increased prevalence in these countries too [1]. Although the pathogenesis of the disease is still not well known, its prevalence is increasing throughout the world, probably because of changes in lifestyle [2].

Diverticular disease can be effectively treated with several treatments, but rifaximin and mesalazine seem to be the most effective [3]. Mesalazine and rifaximin, alone or in combination, are the most used drugs in managing symptomatic uncomplicated $\mathrm{DD}$, especially in treating symptoms and in preventing the first episode of acute diverticulitis (AD) [4, 5]. Moreover, mesalazine seems to be effective also in preventing $\mathrm{AD}$ occurrence/ recurrence in patients with DICA 2 score at endoscopy [6], alone or in combination with rifaximin. Unfortunately, some patients still experience symptoms following those treatments, often associated with raised fecal calprotectin (FC).

Budesonide is a second-generation corticosteroid with low systemic bioavailability after oral administration because of extensive (>90\%) first-pass hepatic metabolism [7]. Budesonide $\mathrm{MMX}^{\mathrm{TM}}$ (multi matrix system) is a new formulation of budesonide that is available as 9 mg delayed- and extendedrelease tablets for oral administration. The MMX formulation has been designed to target orally administered drugs to sites in the distal colon [8]. After positive results obtained by two randomized, placebo-controlled studies [9], in 2017 Budesonide MMX was included in the European Crohn's and Colitis 
Guidelines for treatment of ulcerative colitis (UC) patients with mild to moderate disease who are intolerant or refractory to aminosalicylates [10].

Given the pharmacological characteristics of budesonide $\mathrm{MMX}^{\mathrm{TM}}$, the aim of this study was to assess the efficacy of this formulation in managing symptoms in patients with endoscopic diagnosis of DD and not responding to standard treatments.

\section{METHODS}

We performed a post-hoc analysis of the patients enrolled in the DICA prospective study [11]. All patients were at the first diagnosis of DD, which was scored according to DICA classification [12]. All of them were previously treated with standard treatments (mesalazine and/or rifaximin), but these therapeutic approaches failed in controlling symptoms. We analyzed the following symptoms: abdominal pain, meteorism, constipation and diarrhea, scored from 0 to 10 , and FC expression at baseline and after six months. All patients were treated with budesonide $\mathrm{MMX}^{\mathrm{TM}}$ for 4 weeks ( $9 \mathrm{mg} /$ day for 2 weeks, followed by $9 \mathrm{mg}$ every other day for further 2 weeks), followed by mesalazine 2.4 grams/day for 5 months. Also, the occurrence of side effects was recorded.

\section{RESULTS}

The study group consisted of 24 patients ( 18 females and 6 males, median age 64, IQR: 57.5-73.5), all of them previously treated with mesalazine and/or rifaximin. They were equally subdivided between DICA 2 and DICA 3. The most severe symptom was abdominal pain, showing a mean score of 5 (range 4-6). Baseline demographic and clinical characteristics of the patients enrolled are shown in Table I. At 6-month follow-up a significant reduction in symptomatic score of all symptoms assessed was observed (abdominal pain and meteorism: $\mathrm{p}<$ 0.001; constipation: $\mathrm{p}=0.007$ ) (Fig. 1).

Median (IQR) FC level was $244.5(171.5-322.0) \mu \mathrm{g} / \mathrm{g}$ at baseline and 51.0 (IQR, 35.5-61.5) $\mu \mathrm{g} / \mathrm{g}(\mathrm{p}<0.001$, Kruskal-Wallis test) at 6-month follow up. Significantly, no side effects were recorded during the follow-up.

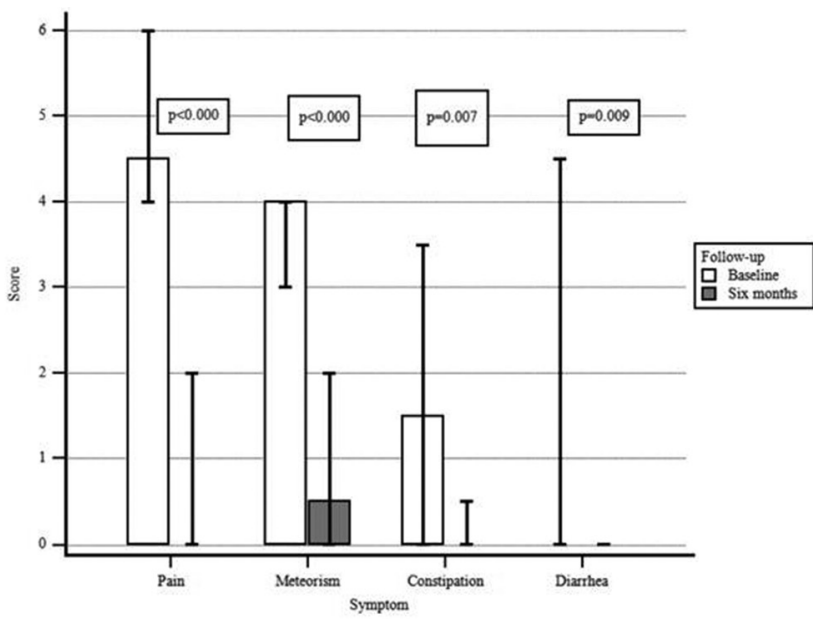

Fig. 1. Symptomatic score at the beginning and after 6 months of follow-up.
Table I. Baseline demographic and clinical characteristics of patients with diverticular disease $(\mathrm{n}=24)$.

\begin{tabular}{lc}
\hline Age & $64(57.5-73.5)$ \\
Gender, female & $18(66.7)$ \\
BMI, kg/m ${ }^{2}$ & $25.2(23.4-28.5)$ \\
Smoking & $4(16.7)$ \\
Appendectomy & $4(16.7)$ \\
Presence of co-morbidities & $8(33.3)$ \\
Charlson's score $>1$ & $3(37.5)$ \\
Previous therapy & \\
Mesalazine & $12(50.0)$ \\
Rifaximin & $7(29.2)$ \\
Mesalazine + rifaximin & $5(20.8)$ \\
DICA score & \\
2 & $12(50.0)$ \\
3 & $12(50.0)$ \\
Symptoms & \\
Abdominal pain & $5(4-6)$ \\
Meteorism & $4(3-4)$ \\
Constipation & $2(0-3)$ \\
Diarrhea & $0(0-4)$ \\
Fecal calprotectin $(\mu \mathrm{g} / \mathrm{g})$ & $244.5(171.5-322.0)$ \\
\hline Values are expressed as number (percentage) for categorical variables and as \\
median (interquartile range) for continuous variables. DICA, Diverticular \\
Inflammation and Complication Assessment; BMI, body mass index \\
\end{tabular}

\section{DISCUSSION}

One of the main clinical challenges is how to manage DICA 2 and 3 patients who failed to obtain significant symptoms improvement after treatment with mesalazine and/or rifaximin.

The first question is why those therapies failed. It is hypothesized that the inflammation is not only limited to the mucosa, but also to the sub-mucosa. Since rifaximin works mainly in the lumen, restoring dysbiosis [13], and mesalazine works mainly in the mucosa by its activation to $\mathrm{N}$-acetyl-5ASA [14], both these drugs could be ineffective in controlling inflammation in DICA 2 and DICA 3 patients.

The second question is how to treat those patients not responding to mesalazine and/or rifaximin. Hypothetically, we should use a drug that crosses the colonic wall, as steroids. However, steroids increase the risk of $\mathrm{AD}$ and its complications $[15,16]$. Treatment with budesonide $\mathrm{MMX}^{\mathrm{TM}}$ could be an interesting option. As stated, the MMX formulation permits to discharge the drug to sites in the distal colon [8], and budesonide $\mathrm{MMX}^{\mathrm{TM}}$ has been advised by ECCO Guidelines for UC patients who are intolerant or refractory to aminosalicylates [10].

The results of this study confirm that budesonide $\mathrm{MMX}^{\mathrm{TM}}$ could be an option in treating patients with endoscopic diagnosis of DD and not responding to standard treatments. In fact, it seems to be effective in obtaining symptoms' control and dropping of FC in patients with DD and not responding to standard treatments. These results are probably linked to the budesonide use rather than the only $\mathrm{MMX}^{\mathrm{TM}}$ mechanism of drug discharge. In fact, the $\mathrm{MMX}^{\mathrm{TM}}$ technology was already used in 
assessing the efficacy of mesalazine $\mathrm{MMX}^{\mathrm{TM}}$ in preventing $\mathrm{AD}$ recurrence (PREVENT 1 and PREVENT 2 trials). Both trials failed in reaching primary end-point [17], probably due the high number of patients enrolled after multiple (more than two) episodes of $\mathrm{AD}$ [18]. Recurrent episodes of $\mathrm{AD}$ might cause progressive fibrosis of the colon with persistent inflammation in the deeper layers of the colonic wall, explaining therefore why the mesalazine, which works only in the colonic mucosa, failed despite the higher colonic concentration guaranteed by the $\mathrm{MMX}^{\mathrm{TM}}$ technology [18].

In patients diagnosed with DD (DICA 2 and DICA 3), not responding to standard treatments, budesonide $\mathrm{MMX}^{\mathrm{TM}}$, seems to be a promising option. Although limited by the low number of patients treated, this observational study shows for the first time that budesonide $\mathrm{MMX}^{\mathrm{TM}}$ may be effectively used in these patients. Other randomized clinical trials are needed to confirm those preliminary results, as well as to define whether it should be used alone or in combination with other treatments.

Conflicts of interest: The authors declare that they have no conflict of interest.

\section{REFERENCES}

1. Tursi A. Diverticulosis today: unfashionable and still under-researched. Therap Adv Gastroenterol 2016;9:213-228. doi:10.1177/1756283X15621228

2. Weizman A, Nguyen GC. Diverticular Disease: epidemiology and management. Can J Gastroenterol 2011;25:305-309. doi:10.1155/2011/795241

3. Tursi A, Papa A, Danese S. Review article: the pathophysiology and medical management of diverticulosis and diverticular disease of the colon. Aliment Pharmacol Ther 2015;42:664-684. doi:10.1111/apt.13322

4. Picchio M, Elisei W, Tursi A. Mesalazine to treat symptomatic uncomplicated diverticular disease and to prevent acute diverticulitis occurrence. A systematic review with meta-analysis of randomized, placebo-controlled trials. J Gastrointestin Liver Dis 2018;27:291-297. doi:10.15403/jgld.2014.1121.273.pic

5. Tursi A, Picchio M, Elisei W, Di Mario F, Scarpignato C, Brandimarte G. Management of Patients With Diverticulosis and Diverticular Disease: Consensus Statements From the 2nd International Symposium on Diverticular Disease. J Clin Gastroenterol 2016;50 Suppl 1:S101-S107. doi:10.1097/MCG.0000000000000654

6. Tursi A, Brandimarte G, Di Mario F, et al. Predictive value of the Diverticular Inflammation and Complication Assessment (DICA) endoscopic classification on the outcome of diverticular disease of the colon: An international study. United European Gastroenterol J 2016;4:604-613. doi:10.1177/2050640615617636
7. Ryrfeldt A, Andersson P, Edsbäcker S, Tönnesson M, Davies D, Pauwels R. Pharmacokinetics and metabolism of budesonide, a selective glucocorticoid. Eur J Respir Dis Suppl 1982;122:86-95.

8. Fiorino G, Fries W, De La Rue SA, Malesci AC, Repici A, Danese S. New drug delivery systems in inflammatory bowel disease: $\mathrm{MMX}^{\mathrm{TM}}$ and tailored delivery to the gut. Curr Med Chem 2010;17:1851-1857. doi: 10.2174/092986710791111170

9. Sandborn WJ, Kamm MA, Lichtenstein GR, Lyne A, Butler T, Joseph RE. MMX Multi Matrix System mesalazine for the induction of remission in patients with mild-to-moderate ulcerative colitis: a combined analysis of two randomized, double-blind, placebo-controlled trials. Aliment Pharmacol Ther 2007;26:205-215. doi:10.1111/j.13652036.2007.03361.x

10. Harbord M, Eliakim R, Bettenworth D, et al. Third European Evidencebased Consensus on Diagnosis and Management of Ulcerative Colitis. Part 2: Current Management. J Crohns Colitis 2017;11:769-784. doi:10.1093/ecco-jcc/jjx009

11. Tursi A, Brandimarte G, Di Mario F, et al. P.02.12 Predictive value of the "DICA" endoscopic classification on the outcome of diverticular disease of the colon: a 1-year analysis from the international, multicenter, prospective study. Dig Liver Dis 2019;51 (Suppl 2):e152-e153. doi:10.1016/S1590-8658(19)30297-X

12. Tursi A, Brandimarte G, Di Mario F, et al. Development and validation of an endoscopic classification of diverticular disease of the colon: the DICA classification. Dig Dis 2015;33:68-76. doi:10.1159/000366039

13. Tursi A, Scarpignato C, Brandimarte G, Di Mario F, Lanas A. Rifaximin for the management of colonic diverticular disease:far beyond a simple antibiotic. J Gastrointestin Liver Dis 2018;27:351-355. doi:10.15403/ jgld.2014.1121.274.rif

14. Lichtenstein GR, Kamm MA. Review article: 5-aminosalicylate formulations for the treatment of ulcerative colitis--methods of comparing release rates and delivery of 5-aminosalicylate to the colonic mucosa. Aliment Pharmacol Ther 2008;28:663-673. doi:10.1111/j.13652036.2008.03751.x

15. Bolkenstein HE, van de Wall BJM, Consten ECJ, Broeders IAMJ, Draaisma WA. Risk factors for complicated diverticulitis: systematic review and meta-analysis. Int J Colorectal Dis 2017;32:1375-1383. doi:10.1007/s00384-017-2872-y

16. Jaung R, Kularatna M, Robertson JP, et al. Uncomplicated Acute Diverticulitis: Identifying Risk Factors for Severe Outcomes. World J Surg 2017;41:2258-2265. doi:10.1007/s00268-017-4012-9

17. Raskin JB, Kamm MA, Jamal MM, et al. Mesalamine did not prevent recurrent diverticulitis in phase 3 controlled trials. Gastroenterology 2014;147:793-802. doi:10.1053/j.gastro.2014.07.004

18. Tursi A, Danese S. Preventing diverticulitis recurrence by selecting the right therapy for a complex disease. Gastroenterology 2014;147:733-736. doi:10.1053/j.gastro.2014.08.022 